\title{
Células madre obtenidas de dientes con retención prolongada
}

\author{
Nayara Nila de Oliveira Rodrigues, ${ }^{1}$ \\ Carolina Rocha Augusto, ${ }^{2}$ \\ Karla Mayra Rezende, ${ }^{3}$ \\ Monicque da Silva Gonçalves. ${ }^{4}$
}

\section{Resumen}

Debido a su fácil accesibilidad, recolección menos invasiva, menos restricciones éticas asociadas con la diferenciación en líneas múltiples más grandes y más rápidas que las de los dientes permanentes, las células madre han ganado mayor notoriedad e inversión en investigación. Actualmente, se ha demostrado que estas células son potenciales en el tratamiento regenerativo de tejidos de numerosas patologías. Caso clínico: Presentar un caso clínico de extracción de dientes con retención prolongada de un niño varón de 7 años como una posible forma de obtener células madre pulpares. Después del diagnóstico y la radiografía, en la que tenía $1 / 3$ raíces, la cirugía fue la opción de tratamiento. Inmediatamente después de la extracción, los dientes se colocaron en un tubo de ensayo con medio de transporte y se enviaron a un laboratorio de cultivo celular. La pulpa dental se retiró con la ayuda de archivo endodóntica y se colocó para cultivo celular. El comienzo de la proliferación comenzó después de 4 días de cultivo. Conclusión: se ha demostrado que las células madre de dientes deciduos son una alternativa terapéutica prometedora, pero comprender la biología de estas células requiere más pruebas in vivo. En este trabajo concluimos que las células de la pulpa dental en dientes con retención prolongada pueden ser una alternativa para obtener células madre.

Palabras clave: Células madre, pulpa dental, diente primario, odontología pediátrica.

\footnotetext{
${ }^{1}$ Graduada en Odontologia, Universidad Nilton Lins, Manaos, Brasil. ${ }^{2}$ Doctora en Clínica Odontológica - Materiales Dentários (UFRGS) Profesora de Dentística de la Universidad Nilton Lins, Manaos, Brasil. ${ }^{3}$ Doctora en Ciências Odontológicas - con área de concentración en Odontopediatria - FOUSP, PhD-Odontopediatria-FOUSP; Prof. Pós graduación en Odontopediatria FFO-USP y São Leopoldo Mandic, São Apulo, Brasil.

${ }^{4}$ Master en Odontopediatria, San Leopoldo Mandic-SP. Profesora de Odontopediatria de la Universidad Nilton Lins, Manaos, Brasil.
} 


\section{Células tronco obtidas de dentes com retenção prolongada}

\section{Resumo}

As células tronco provenientes da polpa de dentes decíduos, em virtude à sua fácil acessibilidade, coleta menos invasiva, poucas restrições éticas, associados com a diferenciação em multilinhagem maior e mais rápida que as dos dentes permanentes, vêm ganhando mais notoriedade $\mathrm{e}$ investimentos em pesquisas. Atualmente, essas células tem se mostrado potenciais no tratamento regenerativo tecidual de inúmeras patologias. Caso clinico: apresentar um relato de caso da exodontia de dentes com retenção prolongada, de uma criança do sexo masculino de 7 anos de idade como possível forma de obtenção de células tronco pulpares. Após o diagnóstico clínico e radiográfico, no qual apresentavam $1 / 3$ de raízes, a cirurgia foi opção de tratamento. Imediatamente após a remoção os dentes foram colocados em tubo de ensaio como meio de transporte e encaminhados para laboratório de cultivo celular. A polpa dentária foi retirada com ajuda de lima endodôntica e colocada para cultivo celular. $\mathrm{O}$ inicio da proliferação começou após 4 dias de cultivo. Conclusão: As células tronco de dentes decíduos tem se mostrado uma alternativa terapêutica promissora, porém a compreensão da biologia dessas células necessita de mais testes in vivo. Nesse trabalho concluímos que as células da polpa dentária em dentes com retenção prolongada podem ser uma alternativa para obtenção de células tronco.

Palavras chaves: Células-tronco, polpa dentária, dente decíduo, odontopediatria.

Case report

\section{Stem cells obtained from teeth with prolonged retention}

\begin{abstract}
Due to their easy accessibility, less invasive collection, few ethical restrictions associated with differentiation into larger and faster multilining than those of permanent teeth, stem cells have gained greater notoriety and investment in research. Currently, these cells have been shown great potential in tissue regenerative treatment of numerous pathologies. Case report: We present a case report of prolonged teeth retention extraction from a 7-year-old male child
\end{abstract}

as a possible way to obtain pulp stem cells. After clinical and radiographic diagnosis, in which it had $1 / 3$ roots, surgery was the treatment option. Immediately after removal, the teeth were placed in a testing tube as a mean of transportation and sent to a cell culture laboratory. The dental pulp was removed with the help of an endodontic file and placed for cell culture. The beginning of proliferation began after 4 days of cultivation. Conclusion: Deciduous teeth stem cells have been shown to be 
a promising therapeutic alternative, but understanding the biology of these cells requires further testing in vivo. In this paper we concluded that dental pulp cells in teeth in prolonged retention

\section{Introducción}

La ingeniería en tejidos actúa pesquisando $\mathrm{y}$ desenvolviendo nuevas combinaciones celulares visando crear o regenerar tejidos, las células madre $(\mathrm{CT})$ vienen siendo una de sus principales focos de interés debido a su poder de renovación y diferenciación

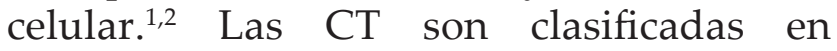
células madre embrionarias (CE) y células madre mesénquimas adultas. ${ }^{3}$ Las CE son totipotentes, de este modo pueden crear todo tipo celular, mientras las células madre mesenquimales adultas posee una limitación, ellas crean apenas algunos tipos celulares, ${ }^{3}$ con todo, ambas tienen una amplia capacidad de proliferación y de promover la regeneración del tejido, tornándolas objeto de pesquisas en muchas áreas de la salud, ${ }^{1,2,4}$ incluyendo la odontologia. ${ }^{2,5-7}$

Una de las primeras publicaciones acerca de las células-madre mesenquimales adultas de origen dental (CTD) fue en el año 2000, donde fue observado en células colectadas de la pulpa dentaria de terceros molares la presencia de células madre mesenquimales similares a las localizadas en la medula ósea. ${ }^{8}$ Se observo un gran aumento en la populación de células clonogenicas en el tejido pulpar, como también células formadoras de colonia de origen pulpar en el mayor número comparado con las CMEs. ${ }^{8}$ Posteriormente, en 2003, al estudiar la pulpa de dientes primarios exfoliados, células altamente proliferativas fueron identificadas, con la capacidad de could be an alternative to obtaining stem cells.

Key words: Stem cells, dental pulp, tooth, deciduous, pediatric dentistry.

diferenciación en una variedad de tipo celulares, incluyendo células neurales, adipocitos y odontoblastos. ${ }^{9}$

A lo largo de casi dos décadas diversos estudios usando CTDs fueron realizados, actualmente se sabe que en la cavidad oral es posible encontrar células madre en: el alveolar, ligamento periodontal, papila dental, folículo dentario, pulpa de los dientes permanentes y primarios exfoliados/extraídos, incluyendo dientes natales. ${ }^{6-10}$ La fácil accesibilidad a las células madre provenientes de la pulpa de los dientes primarios (CTPD) debido a que la recolección es menos invasiva, tiene pocas restricciones éticas al compararlas con la obtención de las células madre embrionarias, esto asociado a una mayor y mas rápida diferenciación que las de los dientes permanentes, ya están haciendo ganar cada vez más notoriedad e inversión en pesquisas., ${ }^{5,10-16}$ Actualmente se sabe que las CTPD en estudios in vitro e in vivo, son eficaz en tratamiento de insuficiencia hepática, ${ }^{4}$ de la encefalomielitis autoinmune experimental, ${ }^{11}$ Parkinson, ${ }^{12}$ Alzheimer ${ }^{13}$ diabetes mellitus, ${ }^{14}$ regeneración del tejido de la córnea, ${ }^{15}$ en la restauración del tejido óseo debido a las enfermedades periodontales, ${ }^{16}$ regeneración de la dentina y de la pulpa dentária. ${ }^{6}$

Para el aislamiento eficaz de las CTPD, es necesario que el diente primario se encuadre en algunas recomendaciones, 
sin embargo, no existe un protocolo establecido para la colecta de CTPD. Es preferible que haya ocurrido en lo máximo 2/3 del proceso de rizólisis, la pulpa debe presentar vitalidad, se prefiere dientes anteriores, extraídos, sin traumatismo, pudiendo haber tejido cariado, aun así, no es lo más indicado. ${ }^{17,18}$ En este sentido, en dientes con retención prolongada (RP) el proceso de rizólisis no ha concluido, de este modo, los mismos permanecen en la cavidad oral mayor tempo del esperado generando una grande probabilidad de alteraciones en la oclusión, siendo necesaria una intervención cirurgica. ${ }^{19}$

El presente estudio tiene como objetivo presentar un relato del caso de la exodoncia de dientes con retención prolongada donados para el aislamiento y cultivo celular, como fuente de células madre.

\section{Reporte de caso}

Paciente de 7 años de edad, genero masculino, $23 \mathrm{~kg}$, se presentó a la clínica de odontopediatría de la Universidad Nilton Lins acompañado por la mamá para un examen semiológico de rutina. Hubo el siguiente reporte "los dientes delanteros que quedan en la parte de abajo, se puso flojo, pero como él no aflojaba totalmente, el diente endureció" fue relatado también que él tenia el hábito de apretar los dientes frecuentemente cuando se ponía nervioso o ansioso.

En el examen clínico intraoral, se observó dentición mixta, todos los dientes limpios, sin embargo, con maloclusión, por esa razón el paciente fue referido para evaluación y tratamiento ortopédico. Conforme la mamá había reportado, los incisivos laterales primarios inferiores estaban en oclusión (Figura 1) y sin movilidad. A través de la radiografía periapical en la región de los incisivos laterales inferiores (Figuras 2 y 3), fue observado que los gérmenes de los incisivos laterales inferiores permanentes se encontraban en la etapa 8 de Nolla, entonces, deberían estar estallando en la cavidad oral.

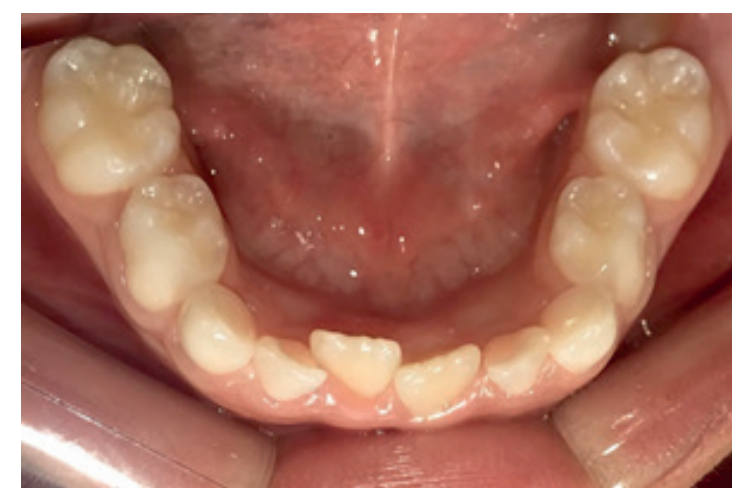

Figura 1: Fotografía intraoral oclusal de la arcada inferior: Se observa la presencia de los incisivos laterales primarios inferiores.

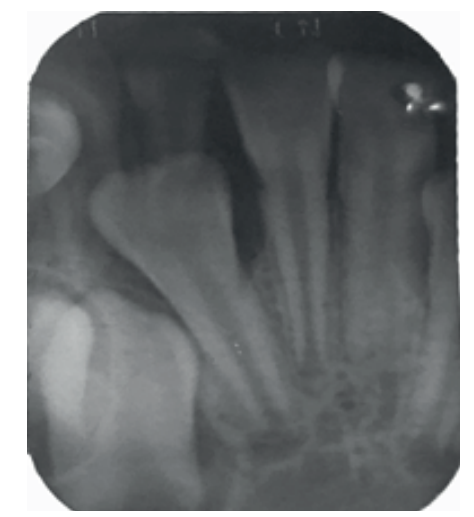

Figura 2: Radiografía periapical del diente 82.

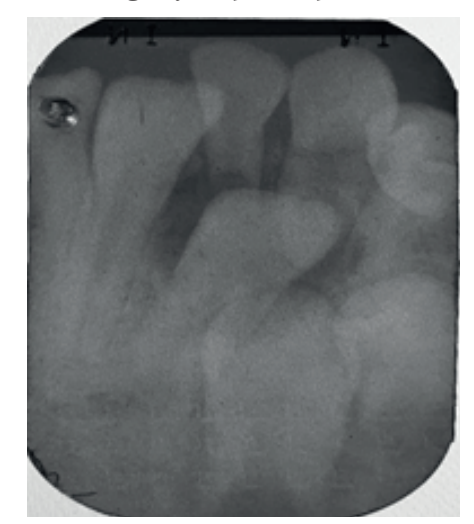

Figura 3: Radiografía periapical del diente 72. 
Al analizar la fase de la etapa de Nolla de los gérmenes de los dientes 32 y 42 así como su posicionamiento y la etapa de rizólisis de los dientes 72 y 82, se optó por la exodoncia. En virtud de la cantidad de la pulpa dentaria presente, esos elementos se tornan viables para la recolección de células madre. La responsable concedió la donación de los dientes primarios para pesquisas sobre las CTPD. Fueron aplicadas las técnicas de condicionamiento comportamental hablar-mostrar-hacer y distracción permitiendo disminuir el estrés y el cansancio emocional del niño, principalmente debido a que la madre había reportado previamente episodios constantes de nerviosismo y ansiedad por parte del niño. Para evitar el movimiento de oclusión y posibles accidentes durante el procedimiento derivados del acto, fue utilizado abridor de boca (Ângelus, Brasil) como contención pasiva.

Para la obtención de células madre de la pulpa de dientes primarios, se recomienda el cuidado para evitar la ruptura de la cadena aséptica y contaminación de la pulpa dentaria por lo que se aplicó el protocolo de la extracción dentaria en odontopediatría.

Se realizó la profilaxis de los dientes a ser extraídos (Figura 4) utilizando pasta profiláctica para remoción del biofilm presente en la estructura dentaria, posteriormente, antisepsia intraoral con clorhexidina $0,12 \%$ y extraoral con iodopovidona tópico, evitando posibles contaminaciones por microorganismos. En seguida, se seco la mucosa, y fue aplicado anestésico tópico en gel de benzocaína durante 3 minutos. Se realizó con anestesia terminal infiltrativa (Figuras 5 e 6) y el bloqueo del nervio incisivo con aguja corta y clorhidrato de lidocaína $2 \%$ con epinefrina 1:100.000, respetando la dosis máxima de dos tubos y medio.

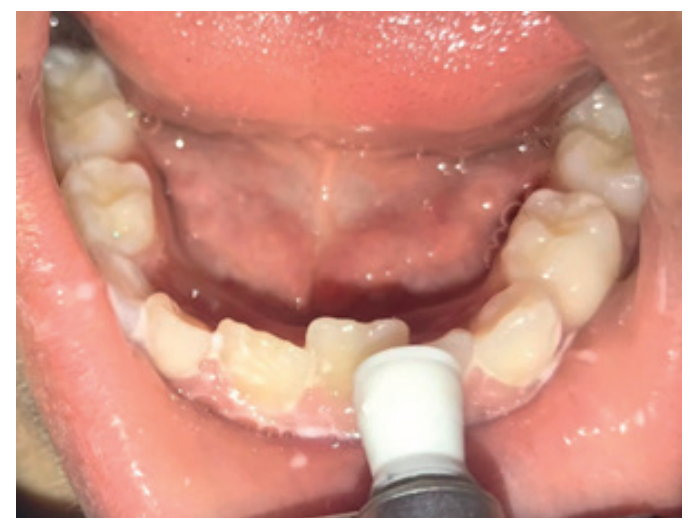

Figura 4: Profilaxis previa a la exodoncia

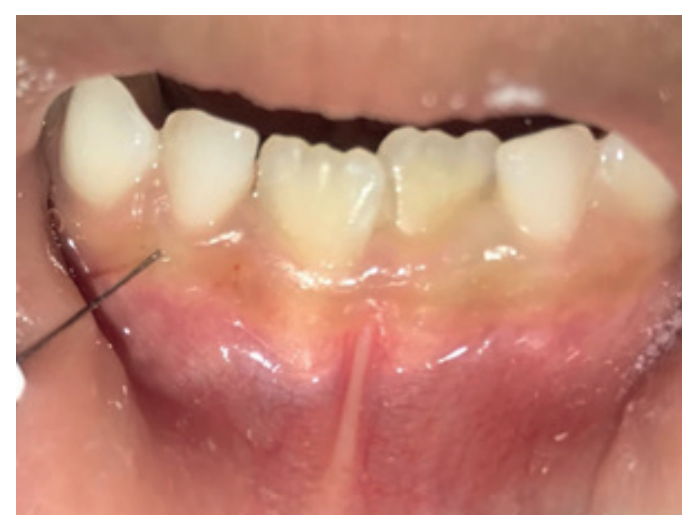

Figura 5: Anestesia infiltrativa en la región del diente 82.

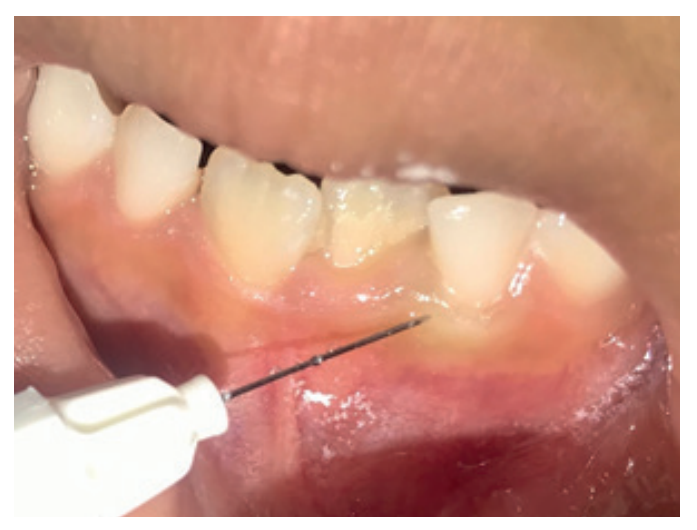

Figura 6: Anestesia infiltrativa en la región del diente 72.

Para la sindesmotomia fue utilizado el elevador de Molt, en la dislocación y exéresis con pinzas (fórceps) 6 infantil. después la exéresis, utilizando la misma 
pinza (fórceps), los dientes fueron inmediatamente transferidos para los tubos de ensayo estéril (Figuras 7 y 8) con solución salina estéril (PBS) (Eurofarma, Brasil), estos después de haber sido guardados y identificados fueron almacenados dentro de un recipiente térmico (Gelotech, Brasil) para la conservación de la pulpa dentaria remanente. No fue necesaria la realización de síntesis, pues los gérmenes de los incisivos laterales permanentes están cerca de estallar. las recomendaciones del posoperatorio fueron todas regulares, dando énfasis en la prevención del mordisqueo

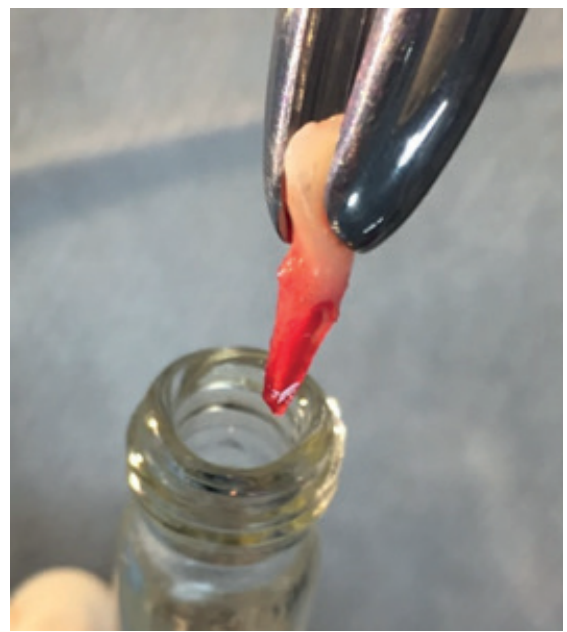

Figura 7: Almacenamiento del diente 82 en el tubo de ensayo.

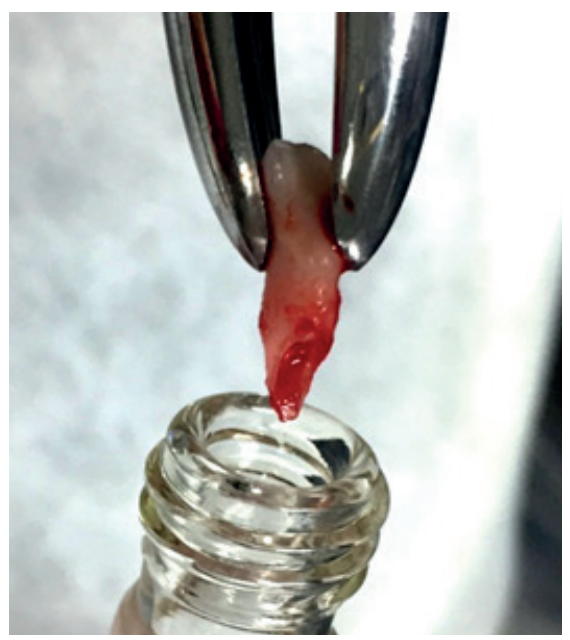

Figura 8: Almacenamiento del diente 72 en el tubo de ensayo. que podría ocurrir debido al labio inferior haber sido anestesiado. Como terapia medicamentosa fue empleado el uso de analgésico (Paracetamol $200 \mathrm{mg} / \mathrm{ml}$ de $6 / 6$ horas, por 24h) debido a la baja lesión del tejido.

Los dientes almacenados en medio de transporte fueron enviados dentro de 24 horas para el laboratorio de cultivo celular, donde fueron realizados los procedimientos para el aislamiento y cultivo de las células madre. Como fueron almacenados en 2 tubos de ensayo, dividido en 2 grupos: uno quedo en medio de PBS y el otro en medio del cultivo celular.

Para el inicio del procedimiento del cultivo primario, los dientes fueron lavados 5 veces con PBS a $2 \%$ del antibiótico y antimicótico $\left(\right.$ Sigma $\left.^{\circledR}\right)$ (Figuras 9 y 10). Primeramente, fue retirada la papila
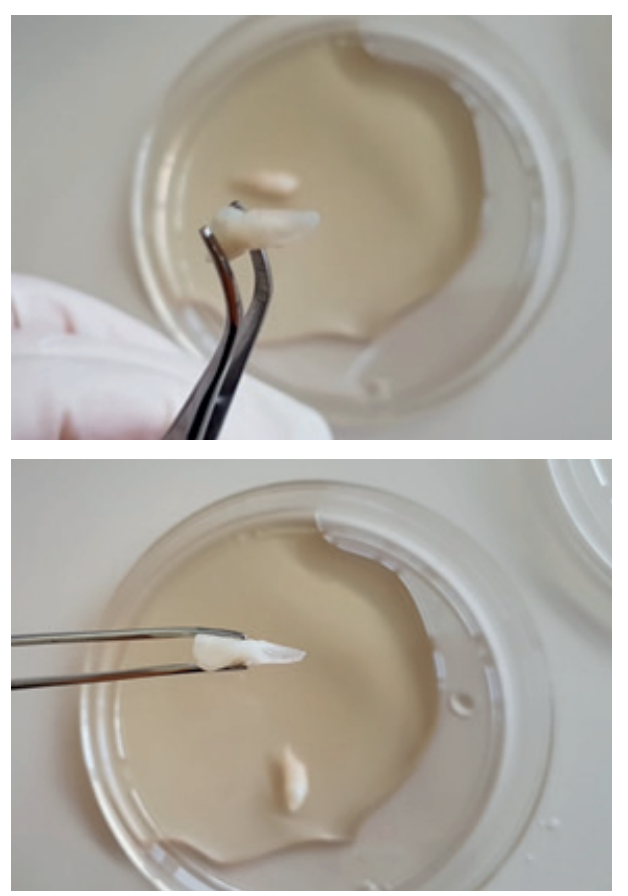

Figura 9 y 10: Al recibir los dientes, estos fueron lavados $5 x$ en $P B S$ para el inicio de la remoción de la pulpa. 
apical utilizando pinza clínica. Y por fin, la remoción de la pulpa dentaria fue realizada a través del foramen apical utilizando lima Kerr número 15.

Los tejidos fueron fragmentados en piezas menores que $1 \mathrm{~mm}^{2}$ y colocadas en placas Petri (Figura 11). Las placas fueron monitoreadas diariamente. Los explantes quedaron en medio del cultivo de manutención constituido de $\alpha$ MEM (Minimum Essential Medium Eagle - $\alpha$ modification) con $1 \%$ de solución antibiótica-antimicótica, 1\% $\beta$-mercaptoetanol y $10 \%$ de suero fetal bovino (FBS), $100 \mu \mathrm{M}$ de ácido ascórbico y $2 \mathrm{mM}$ de L-Glutamina (Glutamax ${ }^{\circledR}$ Gibco).

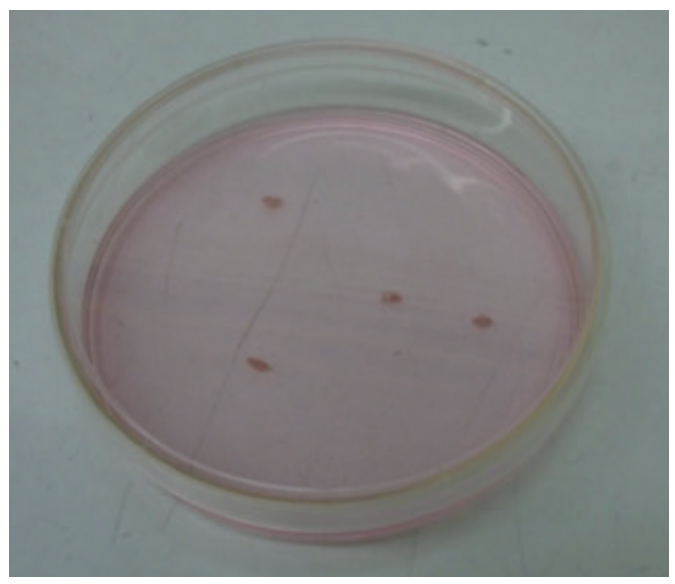

Figura 11: Fragmentos de los tejidos pulpares en la placa de Petri con medio de cultivo celular

Después que las células migraran y se fijaran a la placa, el medio de cultivo fue cambiado, de acuerdo con la necesidad del metabolismo celular. El monitoreo del crecimiento celular fue realizado a través de microscopio invertido de fase y aspectos como vitalidad celular, coloración $\mathrm{y}$ aspecto del medio fueron analizados (Figura 12). Después de alcanzar 75\%

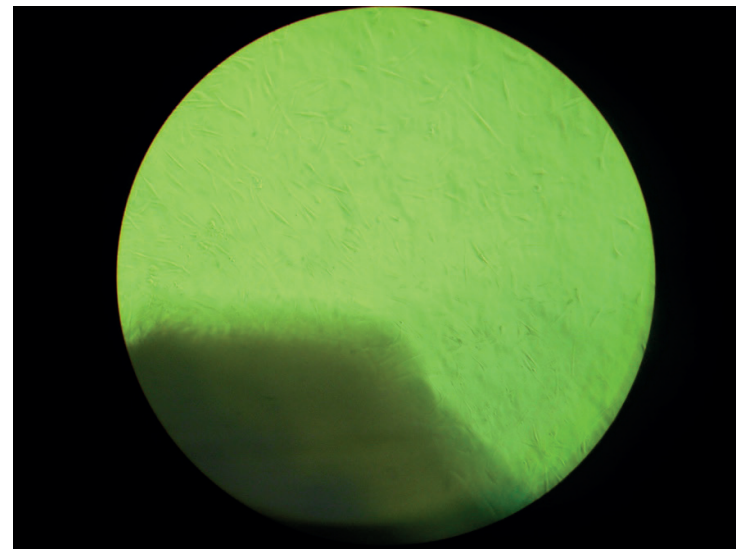

Figura 12: Foto tomada del microscopio invertido de fase. En la porción inferior aparece mitad del tejido pulpar y alrededor varias células saliendo.

de confluencia en la placa, las células fueron subcultivadas de acuerdo con la necesidad de nuevas placas, hasta su uso. El diente que quedo almacenado en solución salina no obtuvo éxito, pues no había generación de células.

\section{Discusión}

Nada es mas notable que el mecanismo entre la transición dentaria primaria y la permanente. Las reabsorciones dentarias se presentan como un problema frecuente en la clínica odontopediátrica. A lo largo del proceso de rizólisis, ocurren algunas modificaciones incluyendo la región del piso de la cámara pulpar, que muestra mayor porosidad y el ápice radicular. ${ }^{20}$ El proceso de reabsorción radicular fisiológica es causado por mecanismos moleculares y celulares que actúan de forma intermitente, sin embargo, factores sistémicos, genéticos o locales pueden acelerar o retardar el proceso de rizólise. ${ }^{21}$ la reabsorción anormal de los dientes primario podrá generar una retención prolongada de ellos, lo que implica en una dificultad para el brote 
del elemento permanente o un desvío de posición esperada. ${ }^{19}$ Danelon et al. (2019) $)^{22}$ mencionaron la importancia del diagnóstico precoz de los dientes con RP y de hacerse la exodoncia para evitar daños a la oclusión, como también el acompañamiento de la erupción de sus sucesores permanentes. La retención prolongada de los incisivos primarios altera la vía normal de erupción de incisivos permanentes, resultando en la impactación, erupción ectópica como por lingual. En el caso de aquí descrito, los laterales primarios mostraban tal característica, en el cual hubo inicio de exfoliación sin embargo estancó y no presento más movilidad. Tal condición fue diagnosticada a través de examen clínico y radiográfico. en la cual los dientes 32 y 42 estaban en etapa 8 de desenvolvimiento radicular entonces sin espacio. Como conducta terapéutica de esta condición, se indica la exodoncia de los elementos retenidos, favoreciendo el proceso de erupción de los sucesores. Con el descubrimiento de las células madre, muchos padres se han preguntando sobre la posibilidad de almacenar esas células para posibles tratamientos. Ya que la terapia aplicada a las células madre provenientes de la pulpa de los dientes primarios es una área en constante crecimiento, se torna cada vez mas en una alternativa para el proceso de regeneración y reparación residual en la área odontológica y médica. ${ }^{2,6} \mathrm{Se}$ sabe que las CTPD debido a sus innumerables ventajas y posibilidades de diferenciación vienen siendo utilizadas en pesquisas del tratamiento de enfermedades neurodegenerativas, enfermedades hepáticas, reconstrucciones óseas, entre otras. ${ }^{1,5,11-16}$ La obtención de esas células madre no posee un protocolo especial, sin embargo, es necesario que el cirujano dentista tenga los conocimiento y tome los cuidados para elección del diente y como mantenerlo hasta el aislamiento de las CTPD. ${ }^{17,18,23}$ Para Sunil et al. (2015) ${ }^{23}$ los molares primarios no son los indicados para la obtención, debido a que contienen menor cantidad de pulpa que los dientes anteriores y poseen mayor probabilidad de contaminarse .

La resorción radicular retardada de los molares puede resultar en una obliteración de la pulpa, haciendo inviable esta para el aislamiento. ${ }^{18}$ en el presente informe del caso, los dos dientes con retención prolongada fueron los incisivos laterales, y estos, de acuerdo a los autores son indicados para exodoncia y obtención de las CTPD. Los dientes que presentan lesiones cariosas, así como, restauración no son los indicados para la recolección, ya que la pulpa dentaria tuvo alteración. Así, de acuerdo con Tsai et al. (2017) $)^{24}$ este aislamiento $y$ cultivo se torna inadecuado, pues la expansión de las CTPD será inferior al ser comparada con la de los dientes saludables, también los dientes con pulpitis o necrosis pulpar no son aprovechables para el aislamiento y cultivo de las CTs. ${ }^{18,25}$ Ambos dientes del presente caso estaban sanos, sin indicios de necrosis pulpar, con características favorables para el aislamiento y expansión celular, desde que fueron almacenado en un medio del cultivo celular adecuado y enviados en menos de 72 horas al laboratorio para iniciar la expansión celular. Eso está de acuerdo con Bernadi et al. $(2011)^{25}$ dientes primarios en proceso de rizólisis tuvieron mayor éxito en el cultivo y expansión celular en comparación con los dientes sin ningún tipo de reabsorción, a pesar de poseer mayor accesibilidad para la obtención, así como también más disponibilidad. Popuri (2018) ${ }^{17}$ dice que $1 / 3$ de raíz es suficiente para el éxito, sin embargo, Sunil et al. $(2015)^{23}$ comentan 
que dientes primarios con $2 / 3$ de raíz son preferibles, pues las posibilidades de éxito aumentan. Para Nóbrega et al. (2018) ${ }^{26}$ la perdida precoz de los dientes primarios es causa de la disminución de la longitud del arco, la migración de los dientes vecinos al espacio originado, teniendo como consecuencia problemas en la masticación, fonación, comprometiendo la estética y afectando psicológicamente al niño. Entonces, la extracción precoz con finalidad de obtención de CTPD no es recomendada, de esta manera, los dientes con retención prolongada representan alguna ventaja para el paciente. La literatura concuerda que los dientes primarios necesitan tener algún grado de reabsorción fisiológica y no infeccioso, por tanto, no debería estar en etapa avanzada, pero difieren en cuanto a la cantidad ideal de la raíz para la obtención. . $^{1723,24}$

Para Pilbauerová et al. (2018) ${ }^{27}$ después de la exodoncia, los dientes primarios nescesitan ser sumergidos en la solución del medio de cultivo celular apropiado para que las células lleguen viables para su manipulación en el laboratorio. El medio de transporte para el cultivo de esas células fue publicado por Gronthos et al., ${ }^{8}$ siendo el protocolo mas utilizado, y el que fue realizado en esta pesquisa de caso clinico. $\mathrm{Al}$ contar con 2 dientes, dejamos uno en ese medio de cultivo celular y el otro fue almacenado en solución salina PBS para verificar si habría apoptosis celular o no como descrito por Eubanks et al., 2014..$^{28}$ Así, en la fase de aislamiento, fue posible la expansión de las células provenientes del diente almacenado en medio del cultivo celular, y no hubo éxito en la expansión celular del diente almacenado en solución salina, es decir que para el transporte de células este medio no es recomendable pues torna inviable la sobrevivencia celular. Así, ese trabajo muestra, por medio de este caso clinico, que dientes con retención prolongada y almacenados en medio de cultivo apropiado pueden ser una alternativa para obtención de células madre de un material que hasta entonces terminaba como desecho biológico. Este trabajo puede ayudar a los odontopediatras a entender y practicar la correcta forma de almacenar estas células para ser trasladadas al laboratório, y orientar a los padres sobre la adecuada obtención de las células madre dentales, orientando a los padres la forma correcta como ocurre la obtención de células madre dentales.

\section{Conclusión}

Los dientes con retención prolongada pueden ser una fuente de células madre Si son correctamente almacenados en un medio de cultivo celular apropiado y transportados en un tiempo ideal para su manejo en el laboratório.

Se describen técnicas básicas pero fundamentales, para que se puedan llevar a cabo pruebas in vitro, in vivo en estudios clínicos randomizados en el futuro, con el objetivo de tornar su uso en diversos tratamientos.

\section{Referencias bibliográficas}

1. Leyendecker J, Gomes P, Lazzaretti F, Franco B. The use of human dental pulp stem cells for in vivo bone tissue engineering: a systematic review. J Tissue Eng. 2018; 9: 1-18.

2. Kaneko T, Gu B, Sone P, Zam S, Murano H, Zaw Z, et al. Dental pulp tissue engineering using mesenchymal stem cells: a review with a protocol. Stem Cells Rev and Rep. 2018; 14: 668-76.

3. Kobolak J, Dinnyes A, Memic A, Khademnhosseini A, Mobasheri A. Mesenchymal stem cells: Identification, phenotypic carcaterization, biological properties and potential for regenerative medicine through biomaterial micro-engineering of their niche. AMST. 2016; 62-8. 
4. Yamaza T, Alatas F, Yuniarth R, Yamaza H, Fujiyoshi J, Yanagi Y, et al. In vivo hepatogenic capacity and therapeutic potential of stem cells from human exfoliated deciduous teeth in liver fibrosis in mice. Stem Cells Res Ther. 2015; 6(171): 2-16.

5. Morotomi T, Washio A, Kitamura C. Current and future options for dental pulp therapy. JPN Dent Sci Rev. 2019; 55: 5-11.

6. Zhai Q, Dong Z, Wang W, Li B, Jin Y. Dental stem cell and dental tissue regeneration. Front Med. 2019; 13(2): 152-9.

7. Rezende K, Imparato J, França D, Rocha M, Bönecker M. Dental pulp stem cells from natal teeth: isolation and morphological study. JCDR. 2018; 12(3): 46-9.

8. Gronthos S, Mankani M, Brahim J, Robey P, Shi S. Postnatal human dental pulp stem cells (DPSCs) in vitro and in vivo. Proc Natl Acad Sci USA. 2000; 97(25): 13625-30.

9. Miura M, Gronthos S, Zhao M, Lu B, Fisher L, Robey P, et al. SHED: stem cells from human exfoliated deciduous teeth. PNAS. 2003; 100(10): 5807-12.

10. Egusa H, Sonoyama W, Nishimura M, Atsuta I, Akiyama K. Stem cells in dentistry- part I: stem cell sources. JPR. 2012; 56: 151-65.

11. Shimojima C, Takeuchi H, Jin S, Parajuli B, Hattori H, Suzumura A, et al. Conditioned medium from the stem cells of human exfoliated deciduous teeth ameliorates experimental autoimmune encephalomyelitis. J Immunol. 2016; 196(10): 4164-71.

12. Fujii H, Matsubara K, Sakai K, Ito M, Ohno K, Ueda M, et al. Dopaminergic differentiation of stem cells from human deciduous teeth and their therapeutic benefits for Parkinsonian rats. Brain Res. 2015 jul.; 1613: 59-72.

13. Wang F, Jia Y, Liu J, Zhai J, Cao N, Yue W, et al. Dental pulp stem cells promote regeneration of damaged neuron cells on the cellular model of Alzheimer's disease. Cell Biol Int. 2017; 639-50.

14. Omi M, Hata M, Nakamura N, Miyabe M, Ozawa S, Nukada H, et al. Transplantation of dental pulp stem cells improves long-term diabetic polyneuropathy together with improvement of nerve morphometrical evaluation. Stem Cells Res Ther. 2017; 8(219): 1-19.

15. Kushnerev E, Shawcross S, Sothirachagan S, Carley F, Brahma A, Yates J, et al. Regeneration of corneal epithelium with dental pulp stem cells using a contact lens delivery system. IOVS. 2016 oct.; 57(13): 5192-6.

16. Hernández-Monjaraz B, Santiago-Osorio E, Ledesma-Martínez E, Alcauter-Zavala A, Mendoza-Núñez V. Retrieval of a periodontally compromised tooth by allogeneic grafting of mesenchymal stem cells from dental pulp: a case report. JIMR. 2018; 46(7): 2983-93.

17. Popuri S. Concerns of a pediatric dentist in dental stem cells: an overview. Open Dent J. 2018; 12: 596-604.

18. Zainuri M, Rutri R, Bachtiar E. Establishing methods for isolation of stem cells from human exfoliated deciduous from carious deciduous teeth. Interv Med Appl Sci. 2018; 10(1): 33-7.

19. Corteleti J, Ota C, Sarmento L, Chisté R, Novaes T, Imparato J. Retenção prolongada de dente decíduo por impactação de dente supranumerário em criança de 12 anos. Rev Assoc Paul Cir Dent. 2016; 70(3): 268-72.

20. Rezende, K.M.; Salgado, M.A.C. Exfoliação dos dentes decíduos. In: Imparato, J.C.P. et al. Anuário de Odontopediatria- Integrada e Atual. Napoleão, 2015, 192-208.

21. De Rossi A, De Rossi M. Mecanismos celulares e moleculares envolvidos na reabsorção radicular fisiológica de dentes decíduos. PBOCI. 2010; 10(3): 505-11.

22. Danelon M, Gonçalves E, Ceolin-Araujo H, Báez-Quintero L, Castro FM, Felipe S, et al. Retención de molares primários: diagnóstico, etiologia, tratamiento y relato de caso clínico. Rev Odontopediatr Latinoam. 2019 ene-jun.; 9(1): 66-73.

23. Sunil P, Manikandan R, Muthumurugan, Yoithapprabhunath T, Sivakumar M. Harvesting dental stem cells - overview. J Pharm Bioallied Sci. 2015 aug.; 7(2): S384-S6.

24. Tsai A, Hong H, Lin WR, Fu JF, Chang CC, Wang IK, et al. Isolation of mesenchymal stem cell from human deciduous teeth pulp. Biomed Res Int. 2017; 1-9.

25. Bernardi L, Luisi S, Fernandes R, Dalberto T, Valentim L, Chies J, et al. The isolation of stem cells from human deciduous teeth pulp is related to the physiological process of resorption. JOE. 2011; 37(7): 373-9.

26. Nóbrega M, Barbosa C, Brum S. Implicações da perda precoce em odontopediatria. Revista PróuniverSUS. 2018 jan-jun.; 9(01) 61-7.

27. Pilbauerová N, Suchánek J. Cryopreservation of dental stem cells. Acta Med. 2018; 61(1): 1-7.

28. Eubanks E, Tarle S, Kaigler D. Tooth Storage, dental pulp stem cell isolation, and clinical scale expansion without animal sérum. JOE. 2014 may.; 40(5): 652-7.

Recibido: 15/10/2019

Aceptado: 18/01/2020

Correspondencia: Nayara Nila de Oliveira Rodrigues correo: nayaranillaa@gmail.com 